\title{
4D Quantitative Image Analysis of Cancer Cell Invasion in a Brain Microenvironment Using ImageJ Software
}

\author{
John Gamble ${ }^{1}$, Robert Tanguay ${ }^{2}$ and Juliet A. Greenwood ${ }^{1}$ \\ 1. Oregon State University, Biochemistry and Biophysics Department, Corvallis, OR, USA. \\ 2. Oregon State University, Department of Environmental and Molecular Toxicology, Corvallis, OR, \\ USA.
}

Acquisition of quantitative data of individual tumor cell invasion within live brain environment is currently limited. Individual cell monitoring is needed to understand cellular mechanisms for aggressive cancer behavior so that these mechanisms can be targeted or exploited for therapies. While numerous in vitro systems are well adapted to elucidate these mechanisms, they lack a dynamic environment that present numerous cell signals, mechanical forces and host cell interactions that combine to provide complex conditions that influence cell behavior. It is this complex microenvironment that cancer is found in humans and therefore it provides the optimal conditions for studying tumor cell invasion. Zebrafish have gained traction as a vertebrate animal model for cancer studies where at three days of age, larvae have functional vasculature and compartmentalization of the brain that can provide transplanted human brain tumor cells a microenvironment that recapitulates brain conditions. With their translucent and small confided brain, tumor cells can be monitored via fluorescent microscopy in extreme detail with visual access to the entire brain. To study glioblastoma (GBM), a very aggressive and deadly brain cancer, our lab has developed an in vivo model where fluorescently dyed human cancer cells are transplanted into the brain of larval zebrafish to monitor progression of the tumor cells (Figure 1A) [1]. This model led to discoveries in GBM invasion and potential treatments to slow that invasion were made [1,2]. While these discoveries were impactful, they did not provide data for individual invasion mechanisms of tumor cells that were affected by treatments or knockdown of protein expression. To fill this gap, we integrated cell tracking through time-lapse confocal imaging into the model so that transplanted GBM cells within the zebrafish brain microenvironment could be monitored differences in invasive behavior. To accomplish this, larvae with GBM cell transplants were anaesthetized, embedded in low melting point agarose on a glass slide bottom petri dish and covered in anaesthetizing media allowing larvae to survive up to $18 \mathrm{hrs}$. Depending on imaging speed of the microscope, z-stack images of the fluorescent cancer cells within zebrafish brain could be taken every 1 to $10 \mathrm{~min}$ for up to eight larvae. Detailed 4D images of the entire tumor cell population in the brain microenvironment were produced.

Using Image J software (Fiji), 4D images of the population of individual tumor cells in larva brains can be automatically tracked to provide a litany of quantifiable data [3]. After performing drift correction using the "3D Drift Correction" plugin to remove any movement not attributed to the tumor cells, the Trackmate plugin can be used to methodically detect and track the tumor cells as they move throughout the brain $[4,5]$. Trackmate uses consecutive modules that identify objects in $3 \mathrm{D}$, creates linkages between the same object from time-point to time-point and then compiles object tracks that represent, in this case, cells movement throughout the brain over time (Figure 1B, C, D). Numerous settings are available for all modules that are customizable for differences in cell phenotypes and as well as fluorophores used for tagging cells. Quality of tracking can be assessed visually throughout the process to make ensure proper identification of cells and their movements. Trackmate will generate useful data for each cell such as mean velocity and displacement, but raw 4D position data of individual cells can be exported for other analyses. The resulting data contains information on the invasiveness of individual tumor cells in brain 
tissue. Typically, tumor cell invasion data only provides information on whether a cell is capable of invasion. Data from this method can generate many different quantifiable tumor cell invasion statistics that can help in elucidating specific mechanisms used by cells to maneuver or invade through a brain microenvironment (Table 1). These statistics can be used to help determine in what ways invasion is affected for tumor cells exposed to potential therapies or alterations in protein expression. Parameters for invasiveness can be set to create subpopulations of tumor cells where the subpopulations are seen to have different responses. All this leading to reliable data that can be more easily compared across studies.

\section{References:}

[1] Lal, S., et al., Journal of Neuroscience Research, 90, (2012), p. 769-781.

[2] Wehmas, L. C., et al., Zebrafish, 13, (2016), p. 317-329.

[3] Schindelin, J. et al., Nature Methods, 9, (2012), p. 676-682.

[4] Parslow, A., et al., Journal of Visualized Experiments, (2014).

[5] Tinevez, J.-Y. et al., Methods, (2016).

\begin{tabular}{|l|l|l|}
\hline Cell Statistic & \multicolumn{1}{|c|}{ Description } & \multicolumn{1}{c|}{ Interpretation } \\
\hline Mean Velocity & $\begin{array}{l}\text { Average velocity of cell } \\
\text { throughout imaging }\end{array}$ & $\begin{array}{l}\text { Describing invasive efficiency } \\
\text { based on speed. }\end{array}$ \\
\hline Min Velocity & $\begin{array}{l}\text { Minimum velocity of cell } \\
\text { between time points }\end{array}$ & $\begin{array}{l}\text { Can be used as parameter for } \\
\text { non-invasive cells. }\end{array}$ \\
\hline Max Velocity & $\begin{array}{l}\text { Maximum velocity of cell } \\
\text { between time points }\end{array}$ & $\begin{array}{l}\text { Reveals if invasion potential is } \\
\text { affected once invasion is } \\
\text { initiated. }\end{array}$ \\
\hline Total Distance & $\begin{array}{l}\text { Total distance traveled by } \\
\text { cell }\end{array}$ & $\begin{array}{l}\text { Can be used as parameter of } \\
\text { non-invasive cells. }\end{array}$ \\
\hline Displacement & $\begin{array}{l}\text { Distance from origin to end } \\
\text { position of cell }\end{array}$ & $\begin{array}{l}\text { Can be used as parameter of } \\
\text { non-invasive cells. }\end{array}$ \\
\hline Directionality & $\begin{array}{l}\text { Cell efficiency of traveling } \\
\text { from origin to end position }\end{array}$ & $\begin{array}{l}\text { Describes invasive efficiency } \\
\text { based on distance. }\end{array}$ \\
\hline Invasiveness & Percent time spent invading & Describes aggressiveness of cell. \\
\hline Invasion Rate & $\begin{array}{l}\text { Number of times a cell } \\
\text { initiates invasion for a } \\
\text { length of time }\end{array}$ & $\begin{array}{l}\text { Describes the cells propensity to } \\
\text { invade. }\end{array}$ \\
\hline $\begin{array}{l}\text { Invasion } \\
\text { Initiation Rate }\end{array}$ & $\begin{array}{l}\text { Average time needed to } \\
\text { initiate invasion }\end{array}$ & $\begin{array}{l}\text { Describes quickness of cell to } \\
\text { initiate invasion. }\end{array}$ \\
\hline
\end{tabular}

Table 1. (Above) Summary of quantitative data that can be collected from individual invasive tumor cells using model.

Figure 1. (Right) Glioblastoma cell invasion tracking in zebrafish xenograft. (A) Glioblastoma (GBM) cell transplant site for 3 days post fertilization larva. (B) 2D representation of 3D images of GBM cells invading zebrafish brain. (C) Detection of GBM cells with ImageJ Trackmate plugin are shown with circles. (D) Individual GBM cell tracks shown provide quantitative invasion data for each cell. $50 \mu \mathrm{m}$ scale bars on bottom right of each image.
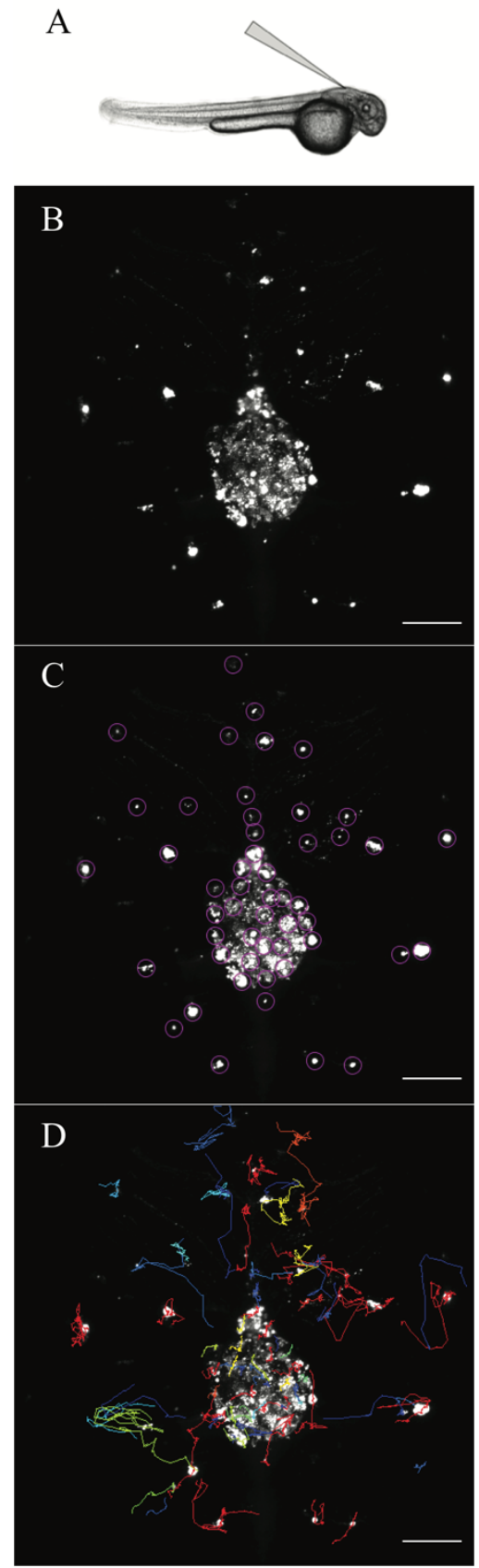